\title{
Study on High and Low Temperature Properties of SBS Modified Asphalt with fasir
}

\section{Gang Peng}

Key Lab of Highway Construction and Maintenance Technology in Loess Region Ministry of Transport, Shanxi Transportation Research Institute, Taiyuan 030006, Shanxi, China

ABSTRACT: In order to study high and low temperature performance of SBS modified asphalt binder with fasir, the softening point test, DSR, ductility test and BBR were tested to detect the changes in its high and low temperature properties according to laboratory tests. Test results showed that softening point and Fail Temperature values of SBS modified asphalt binder with fasir are increased, high temperature performance is greatly improved; but fasir can also reduce its low-temperature cracking resistance. We suggest the reasonable content of fasir is $3 \%$ of the total bituminous mixture quality.

KEYWORD: Warm additive; Modified asphalt; High and low temperature performance

\section{INTRODUCTION}

Warm mix bituminous pavement technology is an emerging road construction technology which is proposed firstly at the 2000 International Asphalt Conference on European. Then many countries began to aggressively research on warm mix asphalt. In 2002, the United States introduced warm mix asphalt technology. In March 2008, NCHRP has begun to research on warm mix asphalt construction performance and emissions and road performance (Project 09247), it is completed in September 2011[1].

Our country began to pay an attention to the Warm mix asphalt pavement technology in 2000. In September 2005, our country built the first bitumi- nous pavement using warm mix technology. The properties of Warm mix asphalt mixture can not only meet the needs of the technical requirements, but also Reduces fuel consumption and emissions of asphalt smoke, environmental pollution and damage to the health of construction workers and other advantages [2].

\section{MATERIAL AND RESEARCH METHOD}

\subsection{Materials}

(1)The experiment used SBS modified asphalt. Table 1 shows the performance of the SBS modified bitumen, tested in accordance with ASTM

Table 1 Properties of SBS modified asphalt binder

\begin{tabular}{ccc}
\hline Test item & Test standards & $\begin{array}{c}\text { Types of asphalt } \\
\text { SBS modified bitumen }\end{array}$ \\
\hline Penetration $\left(25^{\circ} \mathrm{C}\right), 0.1 \mathrm{~mm}$ & ASTM D5 & 69.6 \\
Ductility $\left(15^{\circ} \mathrm{C}\right), \mathrm{cm}$ & ASTM D113 & 32.4 \\
Softening point, ${ }^{\circ} \mathrm{C}$ & ASTM D36 & 69.8 \\
Density $\left(15^{\circ} \mathrm{C}\right), \mathrm{g} / \mathrm{cm}^{3}$ & ASTM D70 & 1.042 \\
Solubility (trichloroethylene), $\%$ & ASTM D2042 & 99.7 \\
PG grade & ASTM D946 & PG70-22 \\
\hline
\end{tabular}

(2)warm mix additive: Fasir is a new warm mix additive, it is usually white solid particles. In the use of the process it can be directly incorporated into the hot bitumen, it will be completely soluble in hot asphalt after simple mixing, and it can effectively reduce the viscosity of asphalt.

\subsection{Research Methods}

(1)Softening point test: Softening point gives an index to the high temperature properties of asphalt, high softening point indicates asphalt' equiviscous temperature is high, which means that the asphalt' high temperature stability is good [3]. 
(2)DSR test: To give an index to the hightemperature performance of SBS modified bitumen with fasir, a TA-AR1500 ${ }^{\mathrm{EX}}$ model DSR was used to conduct temperature sweep experiments with various samples prepared at moderate temperatures of $25^{\circ} \mathrm{C}$ to $80^{\circ} \mathrm{C}$. The rutting factor, $\mathrm{G}^{*} / \sin \delta$ was calculated by DSR computer and liner regression models were then developed between the logarithm of rutting factor and temperature. The failure temperatures, which correspond to the temperatures when rutting factor are equal to $1.0 \mathrm{KPa}$, were educed from the linear regression models [4]. The test results show that the higher failure temperature is, the better high-temperature performance of bitumen will be.

(3)Ductility test: Ductility reflects the extensibility of bitumen Tests were conducted using the LYY7C Asphalt extensometer machine, and the temperatures of tests was $5^{\circ} \mathrm{C}$.

(4)BBR tests: Creep tests were conducted according to SHRP specifications using the bending beam rheometer to estimate cryogenic property of the binders at different temperatures $\left(-12^{\circ} \mathrm{C},-18^{\circ} \mathrm{C}\right.$, $\left.24^{\circ} \mathrm{C}\right)$. Cryogenic property of SBS modified bitumen with fasir was evaluated by creep stiffness (S) and $\mathrm{m}$-value. The $\mathrm{m}$-value is defined as the gradient of the stiffness in logarithmic function at the $60^{\text {th }} \mathrm{sec}-$ ond [5].

\section{RESULTS AND DISCUSSION}

\subsection{Softening point}

Softening point tests were implemented to detect the high-temperature property of SBS modified bitumen with different dosage fasir, the test results are shown in Tab 2.

Tab 2 Softening point of SBS modified asphalt binder $/{ }^{\circ} \mathrm{C}$

\begin{tabular}{lllll}
\hline \multicolumn{2}{l}{ Asphalt binder } & $\begin{array}{l}\text { Softening } \\
\text { point 1 }\end{array}$ & $\begin{array}{l}\text { Softening } \\
\text { point 2 }\end{array}$ & $\begin{array}{l}\text { The aver- } \\
\text { age }\end{array}$ \\
\hline $\begin{array}{l}\text { No addi- } \\
\text { tives }\end{array}$ & $0 \%$ & 69.4 & 68.2 & 68.8 \\
& $2 \%$ & 79.9 & 79.7 & 79.8 \\
Fasir & $3 \%$ & 82.4 & 82.3 & 82.4 \\
& $4 \%$ & 84.6 & 84.5 & 84.6 \\
\hline
\end{tabular}

As shown in Tab 2, through the analysis, the following conclusions can be obtained. Softening point generally increases with the increase of application rate of fasir. The addition of $2 \%$ of the fasir can significantly improve high temperature properties of SBS modified bitumen by $16 \%$. When fasir dosage gradually increased to $3 \%$ and $4 \%$, the increment of SBS modified asphalt binder' softening point is not obvious, an increase of only $3.2 \%$ and $2.6 \%$.

\subsection{Failure temperature}

The rutting factor $\left(\mathrm{G}^{*} / \sin \delta\right)$ was measured between $25^{\circ} \mathrm{C}$ and $80^{\circ} \mathrm{C}$ by each step of $5^{\circ} \mathrm{C}$. According to the measured $\mathrm{G}^{*} / \sin \delta$ of the SBS modified bitumen with four kinds of fasir dosage, the law between the logarithms of $\mathrm{G}^{*} / \sin \delta$ and the temperatures can be get. The failure temperature at $1 \mathrm{kPa}$ was obtained by Linear fitting which is shown in Table 3.

Tab 3 The Failure Temperature of SBS modified asphalt binders

\begin{tabular}{lllll}
\hline & \multicolumn{4}{l}{ SBS modified asphalt binders } \\
\hline Fasir (\%) & 0 & 2 & 3 & 4 \\
Failure Temperature $\left({ }^{\circ} \mathrm{C}\right)$ & 71.48 & 83.06 & 83.08 & 83.08 \\
\hline
\end{tabular}

The Table 3 shows that the failure temperatures of SBS modified asphalt with fasir in it are much bigger than SBS modified asphalt binders with no fasir in it. With the increase of fasir dosage, the failure temperature of SBS modified asphalt binders increases gradually. It reduces the high-temperature performance is getting better. When $2 \%$ fasir is added, the failure temperature of SBS modified asphalt rises $16.2 \%$. While the dosage of fasir gradually increased to $3 \%$ and $4 \%$, the increment of SBS modified asphalt binder' failure temperatures are not obvious compared with $2 \%$ fasir. So, we suggest reasonable content of fasir warm mix agent is $3 \%$.

\subsection{Ductility test}

Ductility tests were used to determine the low temperature performance of SBS modified bitumen with different dosage fasir, the test results are shown in Tab 4.

Tab 4 Ductility of SBS modified asphalt binder $/ \mathrm{cm}$

\begin{tabular}{lllll}
\hline & & ductility 1 & ductility 2 & The average \\
\hline No additives & $0 \%$ & 34.7 & 34.6 & 34.7 \\
& $2 \%$ & 26.8 & 26.6 & 26.7 \\
Fasir & $3 \%$ & 30.5 & 30.4 & 30.5 \\
& $4 \%$ & 34.0 & 34.1 & 34.1 \\
\hline
\end{tabular}

Table 4 shows that the With the increase of Fasir volume, the ductility of SBS modified bitumen increases gradually, but the test results are lower than that of SBS modified bitumen without fasir. The results show adding Fasir into SBS modified bitumen is detrimental to SBS modified bitumen's ductility.

\subsection{BBR tests}

The low-temperature performance of SBS modified bitumen with fasir was detected by BBR tests Test temperature was $-12^{\circ} \mathrm{C},-18^{\circ} \mathrm{C}$ and $-24^{\circ} \mathrm{C}$. The creep stiffness (S) and creep rate (m-value) of each binder were mensurate through the BBR test and the test results are shown in Table 5. 
Tab 5 Creep Stiffness and m-value of SBS modified asphalt binders

\begin{tabular}{|c|c|c|c|c|c|c|c|}
\hline & & $\begin{array}{c}-12^{\circ} \mathrm{C} \\
\text { Stiffness }(\mathrm{MPa})\end{array}$ & $\mathrm{m}$ & $\begin{array}{c}-18^{\circ} \mathrm{C} \\
\text { Stiffness (MPa) }\end{array}$ & $\mathrm{m}$ & $\begin{array}{c}-24^{\circ} \mathrm{C} \\
\text { Stiffness (MPa) }\end{array}$ & $\mathrm{m}$ \\
\hline \multirow[t]{2}{*}{ No additives } & $0 \%$ & 41.1 & 0.452 & 130 & 0.361 & 380 & 0.268 \\
\hline & $2 \%$ & 29.8 & 0.488 & 102 & 0.356 & 396 & 0.256 \\
\hline \multirow[t]{2}{*}{ Fasir } & $3 \%$ & 34.5 & 0.474 & 118 & 0.343 & 437 & 0.213 \\
\hline & $4 \%$ & 42.1 & 0.461 & 132 & 0.326 & 468 & 0.198 \\
\hline
\end{tabular}

From Table 5, it can be seen that With the increase of Fasir volume, the stiffness of SBS modified bitumen enlarges gradually, that means the low temperature behavior of SBS modified bitumen is getting worse. The stiffness of the SBS modified bitumen with fasir slightly decreases at temperature $12^{\circ} \mathrm{C}$ and $-18^{\circ} \mathrm{C}$ when the application rate is no more than $4 \%$, but the stiffness of SBS modified bitumen increases at different temperatures and application rates. That is to say there is an interaction effect of the application rate and temperature on the stiffness of the SBS modified bitumen.

\section{CONCLUSIONS}

(1)By analyzing the softening point and fail temperature values of SBS modified asphalt binders with different dosage of Fasir, it can be seen that fasir can significantly improve high temperature properties of SBS modified bitumen.

(2)From ductility, creep stiffness and m-value, it showed that the low temperature performance of SBS modified bitumen with fasir will be reduced, but it still can meet the specifications. Considering the high and low temperature properties of SBS modified bitumen with fasir, we recommend the appropriate dosage of Fasir is 3\%.

\section{REFERENCES}

[1] Brian D Prowell. The International Technology Scanning Program Warm Mix Asphalt Scan Summary Report[R].Washington DC: Federal Highway Administration, US Department of Transportation, 2007.

[2] Davidson J K. Evotherm Trial: City of Calgary [J]. McAsphalt Engineering Services, 2005, 1-11.

[3] YAN Bao-ping. The Influence of Stabilizer on the Road Performance of SBS Modified Asphalt [J]. Shanxi Science $\&$ Technology of Communications, 2014, 6:5-7. In Chinese

[4] Sam M, Glynn H, and Knanaseelan G. AAPT. 1995; 76: 167-188.

[5] Luan ZS, Lei JQ, Qu P, and Chen HX. Journal of Wuhan University of Technology. 2010; 2: 15-18. In Chinese 